\title{
Should we start vasopressors very early in septic shock?
}

\author{
Gustavo A. Ospina-Tascón ${ }^{1}$, Glenn Hernandez ${ }^{2}$, Jan Bakker ${ }^{2,3,4,5}$ \\ ${ }^{1}$ Department of Intensive Care, Fundación Valle del Lili, Universidad ICESI, Cali, Colombia; ${ }^{2}$ Department of Intensive Care, Pontificia Universidad \\ Católica de Chile, Santiago, Chile; ${ }^{3}$ Department of Pulmonology and Critical Care, Columbia University Medical Center, New York, USA; \\ ${ }^{4}$ Department of Pulmonology and Critical Care, NYU Medical Center, Bellevue Hospital, New York, USA; ${ }^{5}$ Erasmus MC University Medical \\ Center, Rotterdam, The Netherlands \\ Correspondence to: Dr. Gustavo A. Ospina-Tascón, MD, PhD. Department of Intensive Care Medicine, Translational Medicine in Critical Care and \\ Experimental Surgery Laboratory, Fundación Valle del Lili, Universidad ICESI, Av. Simón Bolívar Cra. 98, Cali, Colombia. \\ Email: gusospin@gmail.com. \\ Provenance and Peer Review: This article was commissioned and reviewed by the Section Editor Xue-Zhong Xing [National Cancer Center (NCC)/ \\ Cancer Hospital, Chinese Academy of Medical Sciences (CAMS) and Peking Union Medical College (PUMC), Beijing, China]. \\ Comment on: Permpikul C, Tongyoo S, Viarasilpa T, et al. Early Use of Norepinephrine in Septic Shock Resuscitation (CENSER). A Randomized \\ Trial. Am J Respir Crit Care Med 2019;199:1097-105.
}

Submitted Dec 19, 2019. Accepted for publication Jan 13, 2020.

doi: $10.21037 /$ jtd.2020.02.21

View this article at: http://dx.doi.org/10.21037/jtd.2020.02.21

Early detection and prompt reversion of sepsis-induced tissue hypoperfusion are key elements in the treatment of patients with septic shock $(1,2)$. Fluid administration and vasopressor support are considered life-saving interventions aimed to restore macro and microcirculatory derangements induced during shock (2). Certainly, studies on implementation of therapeutic bundles in sepsis (3) and recent randomized controlled trials on early goaldirected therapy in septic shock (4-6) have highlighted the importance of initial fluid loading and reinforce its use as a standard of care. Indeed, current guidelines on sepsis management preserved the recommendation on administration of at least $30 \mathrm{~mL} / \mathrm{kg}$ of IV crystalloids within the first 3 hours of identification of sepsis-induced hypoperfusion (1). Although also considered a "firstline" intervention, vasopressor support is usually used as a rescue therapy when initial fluid loading fails to correct hypotension or when arterial pressure is judged to be insufficient to ensure an adequate tissue perfusion (1). Nevertheless, while initial resuscitation is based on fluid loading, a recent update of sepsis guidelines proposed a "1hour bundle" (7), which includes the use of vasopressors in the case of life-threatening hypotension, during or after fluid resuscitation, to maintain a mean arterial pressure (MAP) at or above $65 \mathrm{mmHg}$. Although this initiative comprises the concept of sepsis as a medical emergency, the level of evidence for this recommendation concerning both the initial volume of fluids and the blood pressure target, remain limited and highly debatable (8).

The basis for the fluid resuscitation builds on the concept that sepsis and septic shock are conditions inducing absolute or absolute or relative hypovolemia due to a combination of external fluid losses, increased capillary leakage and pathological vasodilation. However, fluid administration is not exempt from adverse effects itself, since volume expansion influences extra and intracellular electrolyte composition, acid-base equilibrium, and body volume of distribution. Moreover, when excessively administered, fluids can induce interstitial edema that may then limit oxygen diffusion to the tissues. In addition, it can also interfere with tissue perfusion by increasing downstream pressures and raising pressures surrounding capillary vessels. A number of observational studies suggest that larger volumes of resuscitation fluids and net fluid balances are associated with increased mortality in sepsis (9-21). Other studies have shown that increased downstream pressure is associated with decreased microcirculatory perfusion and increased organ dysfunction $(22,23)$. Nevertheless, although these results question the safety of large-volume of fluids, the risk of confounding in these observations precludes a causality association since more severely ill patients are more prone to receive more intravenous fluids $(24,25)$. 
Limiting excess of fluid administration therefore seems appropriate, but it could be counterbalanced by the thought potential harm of using vasoactive drugs when hypovolemia is still ongoing. Nevertheless, the idea of testing a very early start of vasopressors in patients with suspected infection and hypotension is attractive. In line with this, a recent phase II randomized controlled trial, the CENSER study, tested the hypothesis that an early low-dose of norepinephrine in patients with sepsis and hypotension could increase control of shock defined by a composite of MAP $>65 \mathrm{mmHg}$ plus either urine output $>0.5 \mathrm{~mL} / \mathrm{kg} / \mathrm{min}$ or a lactate decline $>10 \%$ from baseline, when compared with standard care (26). The authors randomized patients with suspected infection and hypotension to early lowdose of norepinephrine $(n=155)$ or placebo $(n=155)$ plus standard care, which included open-label vasopressors. The experimental group received norepinephrine up to $0.05 \mu \mathrm{gr} / \mathrm{kg} \cdot \mathrm{min}^{-1}$ plus open-label vasopressors and fluid resuscitation, while control group received standard care. Finally, the "early low-dose norepinephrine" group achieved the primary goal in $76.1 \%$ vs. $48.4 \%(\mathrm{P}<0.001)$ in the control group. However, there were no significant differences in 28-day mortality. Although very interesting, these results might be highly debatable as the protocol requested the administration of a fixed dose of norepinephrine, which is not the usual way to use vasopressors. Nevertheless, the more rapid control of shock is in line with recent experimental evidence (27).

An early start of vasopressor therapy may have several potential beneficial effects. First, rapid introduction of vasopressor support might shorten the duration of hypotension, which could influence clinical outcomes since duration and severity of hypotension have been associated with increased risk of death in septic patients (28-30). Second, in addition to the net vasopressor effect, norepinephrine may increase cardiac output by increasing preload (31), by improving myocardial contractility (32) and through improvement of ventriculoarterial coupling (33). Third, an increase in diastolic pressure could improve coronary artery perfusion and myocardial dysfunction in septic patients with hypotension (34). Fourth, norepinephrine might increase microcirculatory perfusion in septic shock (35-37), especially when initial microcirculatory blood flow is abnormal (38). Also, microvascular reactivity during ischemia-reperfusion might be significantly improved by restoring arterial pressure with norepinephrine in severe hypotensive septic patients (37). Fifth, the use of norepinephrine has been associated with improved mean arterial pressure, sustained aortic and mesenteric blood flow and better tissue oxygenation when compared with fluid resuscitation alone (39). Moreover, when introduced early, norepinephrine might improve the regional distribution of blood flow to the mesenteric area (39). Sixth, recent experimental data suggest that initial fluid resuscitation might be related with a paradoxical increase in vasopressor requirements and no improvement of any microcirculatory or organ specific marker of perfusion (27). Although the initial fluid resuscitation resulted in a higher cardiac output during the infusion period, they also showed higher lactate values and more severe endothelial damage at the end of the experiment (27). Seventh, it is unlikely that severe hypotension resulting from serious vasodilation could be reversed by simple fluid administration. Instead, unnecessary fluids and harmful fluid accumulation can occur (21). Eighth, most patients with septic shock do not reveal a gross decrease in stressed volume at the beginning of the process, unless of course, there is an evident loss of fluid. Although stressed volume would remain nearly unaltered in some cases, vasodilation would reduce mean systemic filling pressure thus limiting venous return and ultimately reducing cardiac output. Norepinephrine might increase mean systemic filling pressure by changes in venous capacitance thus mobilizing non-stressed to stressed circulatory blood volume (31). Ninth, some observational evidence indicates that delayed start of vasopressors could be related with adverse clinical outcomes (40). However, the recent CENSER trial demonstrated no differences in 28-day mortality when early but non-titrated doses of norepinephrine were administered to patients with suspected infection and hypotension, although a more rapid "control of shock" was apparent (26).

Optimal timing for starting vasopressors (VP) in sepsis has not been adequately tested since guidelines recommend fluids to be administered first. Some physiological reasons supported by observational and experimental studies suggest that an early start of vasopressors could be advantageous. Nevertheless, benefice or harm of the early introduction of vasopressors, even preceding initial fluid loading, remains unanswered. Prospective studies evaluating the impact of very early start of vasopressor support on the development of multiorgan dysfunction and the total volume of resuscitation fluids required during the early phases of septic shock are thus required. 


\section{Acknowledgments}

We thank Dr. Sergio Prada (Centro de Investigaciones clínicas, Fundación Valle del Lili, Cali, Colombia) and Dr. Yuri Takeuchi (Universidad ICESI, Cali, Colombia) for their unconditional support to research.

Funding: None.

\section{Footnote}

Conflicts of Interest: All authors have completed the ICMJE uniform disclosure form (available at http://dx.doi. org/10.21037/jtd.2020.02.21). The authors have no conflicts of interest to declare.

Ethical Statement: The authors are accountable for all aspects of the work in ensuring that questions related to the accuracy or integrity of any part of the work are appropriately investigated and resolved.

Open Access Statement: This is an Open Access article distributed in accordance with the Creative Commons Attribution-NonCommercial-NoDerivs 4.0 International License (CC BY-NC-ND 4.0), which permits the noncommercial replication and distribution of the article with the strict proviso that no changes or edits are made and the original work is properly cited (including links to both the formal publication through the relevant DOI and the license). See: https://creativecommons.org/licenses/by-nc-nd/4.0/.

\section{References}

1. Rhodes A, Evans LE, Alhazzani W, et al. Surviving Sepsis Campaign: International Guidelines for Management of Sepsis and Septic Shock: 2016. Intensive Care Med 2017;43:304-77.

2. Cecconi M, De Backer D, Antonelli M, et al. Consensus on circulatory shock and hemodynamic monitoring. Task force of the European Society of Intensive Care Medicine. Intensive Care Med 2014;40:1795-815.

3. Levy MM, Dellinger RP, Townsend SR, et al. The Surviving Sepsis Campaign: results of an international guideline-based performance improvement program targeting severe sepsis. Crit Care Med 2010;38:367-74.

4. Peake SL, Delaney A, Bailey M, et al. Goal-directed resuscitation for patients with early septic shock. N Engl J Med 2014;371:1496-506.

5. Mouncey PR, Osborn TM, Power GS, et al. Trial of early, goal-directed resuscitation for septic shock. N Engl J Med 2015;372:1301-11.

6. Yealy DM, Kellum JA, Huang DT, et al. A randomized trial of protocol-based care for early septic shock. N Engl J Med 2014;370:1683-93.

7. Levy MM, Evans LE, Rhodes A. The Surviving Sepsis Campaign Bundle: 2018 update. Intensive Care Med 2018;44:925-8.

8. Chen AX, Simpson SQ, Pallin DJ. Sepsis Guidelines. N Engl J Med 2019;380:1369-71.

9. Boyd JH, Forbes J, Nakada TA, et al. Fluid resuscitation in septic shock: a positive fluid balance and elevated central venous pressure are associated with increased mortality. Crit Care Med 2011;39:259-65.

10. Micek ST, McEvoy C, McKenzie M, et al. Fluid balance and cardiac function in septic shock as predictors of hospital mortality. Crit Care 2013;17:R246.

11. Sadaka F, Juarez M, Naydenov S, et al. Fluid resuscitation in septic shock: the effect of increasing fluid balance on mortality. J Intensive Care Med 2014;29:213-7.

12. Acheampong A, Vincent JL. A positive fluid balance is an independent prognostic factor in patients with sepsis. Crit Care 2015;19:251.

13. de Oliveira FS, Freitas FG, Ferreira EM, et al. Positive fluid balance as a prognostic factor for mortality and acute kidney injury in severe sepsis and septic shock. J Crit Care 2015;30:97-101.

14. Kelm DJ, Perrin JT, Cartin-Ceba R, et al. Fluid overload in patients with severe sepsis and septic shock treated with early goal-directed therapy is associated with increased acute need for fluid-related medical interventions and hospital death. Shock 2015;43:68-73.

15. Sakr Y, Rubatto Birri PN, Kotfis K, et al. Higher Fluid Balance Increases the Risk of Death From Sepsis: Results From a Large International Audit. Crit Care Med 2017;45:386-94.

16. Vincent JL, Sakr Y, Sprung CL, et al. Sepsis in European intensive care units: results of the SOAP study. Crit Care Med 2006;34:344-53.

17. Murphy CV, Schramm GE, Doherty JA, et al. The importance of fluid management in acute lung injury secondary to septic shock. Chest 2009;136:102-9.

18. Sirvent JM, Ferri C, Baró A, et al. Fluid balance in sepsis and septic shock as a determining factor of mortality. Am J Emerg Med 2015;33:186-9.

19. Silversides JA, Major E, Ferguson AJ, et al. Conservative fluid management or deresuscitation for patients with sepsis or acute respiratory distress syndrome following the 
resuscitation phase of critical illness: a systematic review and meta-analysis. Intensive Care Med 2017;43:155-70.

20. Smith SH, Perner A. Higher vs. lower fluid volume for septic shock: clinical characteristics and outcome in unselected patients in a prospective, multicenter cohort. Crit Care 2012;16:R76.

21. Marik PE, Linde-Zwirble WT, Bittner EA, et al. Fluid administration in severe sepsis and septic shock, patterns and outcomes: an analysis of a large national database. Intensive Care Med 2017;43:625-32.

22. Vellinga NA, Ince C, Boerma EC. Elevated central venous pressure is associated with impairment of microcirculatory blood flow in sepsis: a hypothesis generating post hoc analysis. BMC Anesthesiol 2013;13:17.

23. Legrand M, Dupuis C, Simon C, et al. Association between systemic hemodynamics and septic acute kidney injury in critically ill patients: a retrospective observational study. Crit Care 2013;17:R278.

24. Sjoding MW, Luo K, Miller MA, et al. When do confounding by indication and inadequate risk adjustment bias critical care studies? A simulation study. Crit Care 2015;19:195.

25. Bosco JL, Silliman RA, Thwin SS, et al. A most stubborn bias: no adjustment method fully resolves confounding by indication in observational studies. J Clin Epidemiol 2010;63:64-74.

26. Permpikul C, Tongyoo S, Viarasilpa T, et al. Early Use of Norepinephrine in Septic Shock Resuscitation (CENSER). A Randomized Trial. Am J Respir Crit Care Med 2019;199:1097-105.

27. Byrne L, Obonyo NG, Diab SD, et al. Unintended Consequences; Fluid Resuscitation Worsens Shock in an Ovine Model of Endotoxemia. Am J Respir Crit Care Med 2018.

28. Varpula M, Tallgren M, Saukkonen K, et al. Hemodynamic variables related to outcome in septic shock. Intensive Care Med 2005;31:1066-71.

29. Dünser MW, Takala J, Ulmer H, et al. Arterial blood pressure during early sepsis and outcome. Intensive Care Med 2009;35:1225-33.

30. Maheshwari K, Nathanson BH, Munson SH, et al. The

Cite this article as: Ospina-Tascón GA, Hernandez G, Bakker J. Should we start vasopressors very early in septic shock? J Thorac Dis 2020;12(7):3893-3896. doi: 10.21037/jtd.2020.02.21 relationship between ICU hypotension and in-hospital mortality and morbidity in septic patients. Intensive Care Med 2018;44:857-67.

31. Hamzaoui O, Georger JF, Monnet X, et al. Early administration of norepinephrine increases cardiac preload and cardiac output in septic patients with life-threatening hypotension. Crit Care 2010;14:R142.

32. Hamzaoui O, Jozwiak M, Geffriaud T, et al. Norepinephrine exerts an inotropic effect during the early phase of human septic shock. Br J Anaesth 2018;120:517-24.

33. De Backer D, Pinsky M. Norepinephrine improves cardiac function during septic shock, but why? Br J Anaesth 2018;120:421-4.

34. Ducrocq N, Kimmoun A, Furmaniuk A, et al. Comparison of equipressor doses of norepinephrine, epinephrine, and phenylephrine on septic myocardial dysfunction. Anesthesiology 2012;116:1083-91.

35. Thooft A, Favory R, Salgado DR, et al. Effects of changes in arterial pressure on organ perfusion during septic shock. Crit Care 2011;15:R222.

36. Jhanji S, Stirling S, Patel N, et al. The effect of increasing doses of norepinephrine on tissue oxygenation and microvascular flow in patients with septic shock. Crit Care Med 2009;37:1961-6.

37. Georger JF, Hamzaoui O, Chaari A, et al. Restoring arterial pressure with norepinephrine improves muscle tissue oxygenation assessed by near-infrared spectroscopy in severely hypotensive septic patients. Intensive Care Med 2010;36:1882-9.

38. Dubin A, Pozo MO, Casabella CA, et al. Increasing arterial blood pressure with norepinephrine does not improve microcirculatory blood flow: a prospective study. Crit Care 2009; 13:R92.

39. Sennoun N, Montemont C, Gibot S, et al. Comparative effects of early versus delayed use of norepinephrine in resuscitated endotoxic shock. Crit Care Med 2007;35:1736-40.

40. Bai X, Yu W, Ji W, et al. Early versus delayed administration of norepinephrine in patients with septic shock. Crit Care 2014;18:532. 